\title{
Penulisan Artikel dan Strategi Publikasi di Jurnal Nasional dan Internasional: Usaha Internasionalisasi Perguruan Tinggi
}

\author{
Haerazi ${ }^{\star}$, Lalu Ari Irawan, Arif Rahman, Jupri, \& Moh. Arsyad Arrafii \\ Prodi S2 Pendidikan Bahasa Inggris, FBMB, Universitas Pendidikan Mandalika, Jl. Pemuda \\ No. 59 A, Mataram, Indonesia 83125 \\ *Email Korespondensi: haerazi@ikipmataram.ac.id dan 081803266792
}

Diterima: Februari 2021; Revisi: April 2021; Diterbitkan: Mei 2021

\begin{abstract}
Abstrak
Menulis di jurnal nasional bereputasi dan internasional bereputasi merupakan salah satu cara meningkatkan kolaborasi dan koneksi antarpeniliti, namun masih dianggap sebagai sesuatu yang sulit untuk dilakukan. Pengabdian ini bertujuan untuk membantu peneliti (dosen pemula dan mahasiswa pascasarjana) menulis dan mempublikasikan artikel di jurnal nasional maupun internasional bereputasi secara efektif. Pengabdian ini menerapkan metode Virtual-Based Active Participatory Action. Peserta yang terlibat dalam kegiatan ini berjumlah 332 peserta melalui virtual meeting. 30 peserta terlibat dalam intensive meeting dan didesain dalam sesi Article Schools. Peserta intensive meeting dibatasi berdasarkan kualitas artikel yang direview oleh tim pengabdian. Berdasarkan hasil pelaksanaan pengabdian ini, bahwa dosen pemula dan mahasiswa pascasarjana dapat mengatasi kesulitan dalam menentukan kebaharuan (novelty) penelitian, topik atau isu-isu penelitian yang up-to-date secara nasional dan internasional, mempresentasikan review of related literature dalam artikel dengan baik, dan menentukan jurnal tempat publikasi yang tepat.
\end{abstract}

Kata Kunci: Menulis artikel ilmiah; strategi publikasi, dan perguruan tinggi

\section{Article Writing and Publication Strategies in National and International Journals: Efforts to Internationalize Higher Education}

\begin{abstract}
Writing in reputable national and international journals is one of techniques to improve authors or researchers' collaboration and connection but it is considered as a uneasy action to be done. This dedication aims to help researchers (novice lecturers and postgraduate students) write and publish articles in reputable national and international journals effectively. This service applies the Virtual-Based Active Participatory Action method. Participants involved in the service totaled 332 participants in virtual meetings. Thirty participants were engaged in intensive meetings and were designed in Article Schools sessions. Participants in this intensive meeting are limited based on the quality of the articles reviewed by the service team. Based on the results of this service, the findings show that the novice lecturers and the postgraduate students can diminish their difficulties in determining the novelty of their studies; their topics or research issues are up-to-date nationally and internationally; they overcome their problems in presenting reviews of related literature in articles; and determine the reputable publication journals.
\end{abstract}

Keywords: Writing academic articles; publication strategies; higher education

How to Cite: Haerazi, H., Irawan, L. A., Rahman, A., Jupri, J., \& Arrafii, M. A. (2021). Penulisan Artikel dan Strategi Publikasi di Jurnal Nasional dan Internasional: Usaha Internasionalisasi Perguruan Tinggi. Lumbung Inovasi: Jurnal Pengabdian Kepada Masyarakat, 6(1), 1-9. https://doi.org/10.36312/linov.v6i1.469

https://doi.org/10.36312/linov.v6i1.469

Copyright@ 2021, Haerazi et al This is an open-access article under the CC-BY License. (C) (i)

\section{PENDAHULUAN}

Menulis karya ilmiah bagi sebagian akademisi di perguruan tinggi adalah suatu hal yang mudah dilakukan bila sudah terbiasa publikasi baik di jurnal nasional dan internasional (Haerazi et al., 2020). Namun, bagi kalangan dosen dan mahasiswa pasca menjadi momok 
bagi mereka di saat publikasi ilmiah di jurnal bereputasi menjadi prasyarat ujian dan kenaikan pangkat akademik dosen (Haerazi, 2020). Hal ini terjadi karena budaya menulis bagi mereka masih rendah. Dengan demikian, publikasi artikel ilmiah seringkali menjadi penghambat bagi mahasiswa untuk menyelesaikan studinya dengan tepat waktu. Begitu juga dosen untuk kenaikan jenjang karirnya menjadi terhambat lajunya.

Menulis artikel untuk dipublikasikan di jurnal bereputasi tidak sama dengan menulis artikel untuk diterbitkan di koran. Bahasa dan penyajiannya cukup berbeda. Menurut Haerazi and Irawan (2019), artikel ilmiah adalah hasil tulisan yang dikomposisikan secara jelas, ringkas, fokus, terstruktur, and didukung oleh bukti baik empirical evidence maupun theoretical evidence. Tujuan penyajian ini adalah untuk membantu pembaca memahami ide yang disampaikan oleh penulis. Penulis yang baik adalah yang mampu memberikan pemahaman yang baik kepada pembacanya. Dalam menulis, ada tiga kompetensi yang harus dilibatkan oleh penulis, kompetensi linguistik, kompetensi kognitif, dan kompetensi sosialbudaya penutur Bahasa yang digunakan (Haerazi et al., 2018; Crosthwaite, 2018).

Dosen pemula dan mahasiswa seringkali gagal mengakomodasi tiga kompetensi ini dalam dirinya ketika menulis artikel. Kompetensi linguistik menuntut penulis harus menguasai semua aspek kebahasaan dalam merangkai kata, frase, kalimat, dan paragraf sehingga tulisan itu menjadi terbaca dengan kohesi yang tepat (Boyle, Ramsay, \& Struan, 2019). Kompetensi kognitif mengharuskan penulis untuk memiliki kecerdasan dalam memahami objek yang ditulis. Penulis harus memahami objek yang menjadi kajian penelitiannya dengan baik. Dalam konteks ini, penulis dituntut untuk banyak membaca isu-isu yang sedang ditulisnya (Haerazi \& Irawan, 2019; Arsyad \& Adila, 2018). Di samping itu, kompetensi social budaya juga menjadi penting dalam menulis. Kompetensi ini mengacu kepada kemampuan penulis menggunakan dan mengekspresikan Bahasa pengantar yang digunakan sesuai dengan Bahasa penuturnya (Haerazi \& Irawan, 2019).

Tiga kompetensi ini harus didukung dengan pengetahuan dosen dan mahasiswa terkait jenis artikel yang ditulis. Pengabdian ini menitikberatkan perhatiannya pada penulisan artikel berbasis penelitian (Research-based articles). Jadi, menulis artikel dari hasil penelitian yang baik tidak bisa dilakukan dalam satu atau dua hari lalu kemudian penulis diklaim memiliki skill menulis yang sempurna. Penulis diperlukan Latihan menulis secacar terus-menerus (Listyani, 2017). Persoalan mendasar yang penting diketahui oleh seorang penulis adalah sistematika penulisan karya ilmiah. Pengetahuan ini diluar kompetensi yang harus dimiliki oleh penulis. Pengabdian ini memfokuskan pada hal-hal yang mendesak bagi dosen pemula dan mahasiswa pasca untuk publikasi di jurnal bereputasi.

Berdasarkan kebutuhan dosen dan mahasiswa pasca dalam publikasi, pengabdian ini didesain untuk membantu mitra dalam konteks bagaimana mereka menyusun artikel yang berbasis penelitian dan memberikan gambaran terkait sistematika penulisan artikel yang siap dipublikasi. Dengan demikian, solusi yang ditwarkan dalam skema pengabdian aktif partisipasi virtual ini dengan memaparkan sistematika artikel yang terdiri atas Introduction, research method, research findings dan discussion, conclusion, dan references. Sistematika ini disebut dengan IMRAD style. Pengembangan tiga kompetensi Bahasa dan non-bahasa disisipkan dalam setiap latihan menulis baik dari penyusunan kalimat-kalimat sampai kepenulisan paragraf yang komplit.

Penulisan artikel untuk dosen pemula dan mahasiswa pasca dilakukan dengan dua sesi. Sesi online berkaitan dengan pemaparan narasumber terkait materi menulis artikel secara umum. Sesi ini lebih menekankan penguatan pemahaman peserta dibandingkan kegiatan online lainnya (Haerazi et al. 2019). Lalu, sesi kedua dikhususkan bagi artikel yang sudah diseleksi untuk dilakukan diskusi lebih mendalam dengan menggunakan formasi Article Schools. Hal ini dirasa penting dilakukan. Jadi, tujuan pengabdian ini adalah membantu dosen pemula dan mahasiswa pasca untuk publikasi di jurnal nasional dan internasional yang bereputasi. Dengan publikasi ilmiah secara massif, mitra secara tidak mampu menginternasionalisasi perguruan tinggi mitra.

\section{METODE PELAKSANAAN}

Kegiatan pengabdian ini dilakukan dalam bentuk virtual workshop. Maka metode pelaksanaan pelaksanaan workshop ini menggunakan pendekatan Virtual Participatory 
Action. Pendekatan ini dibagi menjadi dua sesi. Sesi pertama pra-pelatihan penulisan karya ilmiah dan sesi kedua adalah Tindakan pelatihan penulisan karya ilmiah (virtual workshop). Adapun langkah-langkah pelaksanaannya dielaborasi sebagai berikut.

1 Pra-pelatihan penulisan karya ilmiah

Untuk menarik minat para dosen dan mahasiswa untuk ikut serta dalam pelatihan ini, tim melakukan sosialisasi kegiatan terlebih dahulu. Peserta disyaratkan untuk melakukan pendaftaran secara online dan/ataupun offline. Jumlah peserta pelatihan dijadikan konsiderasi untuk mendesain skema penyajian materi secara virtual. Peserta dari kalangan dosen terdiri atas 23 dan mahasiswa pasca berjumlah 32 orang. Jadi peserta berjumlah 55 orang yang dinyatakan siap mengikuti virtual workshop. Peserta juga disyaratkan harus memiliki draft artikel untuk didiskusikan atau direview oleh tim apakah layak publikasi atau butuh revisi lebih lanjut.

Berdasarkan jumlah peserta, tim pada tahapan ini mendesain materi virtual workshop agar lebih mudah dipahami oleh peserta. Materi yang disajikan diformulasikan sesuai dengan jenis penelitian yang dilakukan. Berdasarkan analisa draf artikel yang diterima, tim mengklasifikasikan jenis penelitian yang dilakukan oleh peserta. Ada 3 jenis penelitian yang mendominasi, yaitu classroom action research, penelitian experimen, penelitian kualitatif deksriptif, dan pengembangan (R\&D design). Berdasarkan tiga jenis penelitian ini, tim meformulasikan strategi penulisan artikel in line dengan jenis penelitian yang dilakukan. Langkah berikutnya pada tahapan ini adalah menetapkan template secara umum untuk menulis artikel yang siap dipublikasi baik nasional dan internasional yang bereputasi. Setiap template ini dipresentasikan oleh tim atau presenter yang sudah ditetapkan bersama.

2 Tindakan pelatihan virtual workshop

Komponen artikel yang harus disusun oleh peserta meliputi Introduction, Literature Review, Research Method, Research Findings, Discussion, dan References. Dalam penulisan tahapan-tahapan ini, penulis harus mampu menunjukkan fakta masalah yang diteliti, kondisi sebenarnya, peristiwa yang terjadi dengan data yang bisa dibuktikan. Kenyataan yang dihadapi peneliti lalu dikaitkan dengan beberap penelitian yang sudah dilakukan oleh orang lain namun mungkin hasil dan caranya berbeda atau bahkan belum optimal sehingga penting untuk ditindak lanjuti. Untuk membantu peserta, tim secara virtual mengarahkan peserta untuk membuat catatan-catatan berkaitan dengan masalah yang diobservasi, dirasakan, atau dihadapi oleh peneliti.

Dalam menyelesaikan catatan-catatan masalah yang harus dikumpulkan dan ditulis, pemateri memberikan durasi waktu dari 10-15 menit seraya memberikan arahan bagaimana catatan-catatan fakta ini nanti akan menjadi dasar dalam menulis artikel. Setelah itu, peserta dilibatkan dalam menemukan kebaruan dalam penelitiannya. Berdasarkan fakta yang dihadapi dan lalu dikaitkan dengan penelitian terdahulu, peserta diminta untuk menuliskan ekspektasi dalam menyelesaikan masalah tersebut. Mampu menemukan kebaruan penelitian yang ditulis membantu peserta untuk mengetahui solusi yang terbaik yang diharapkan untuk menyelesaikan masalahnya. Di samping itu, peserta menjadi tahu metode penelitian yang tepat untuk mendapatkan data dengan didukung teori yang relevan dengan masalah yang dihadapi.

Menyusun kajian atau landasan teori didasarkan pada variable penelitian yang ada. Peserta secara virtual diminta untuk menunjukkan variable penelitiannya. Berdasarkan inilah peserta menyusun isu-isu yang menjadi kajian teori dalam artikelnya. Disamping itu, peserta Menyusun kajian teori berdasarkan rumusan masalah yang sudah ditetapkan dengan menganalisa topik atau isu-isu yang sedang diuji secara ilmiah. Peserta juga secara virtual dilibatkan dalam aktivitas-aktivitas bagaimana cara menentukan kajian teori yang tepat untuk memahami kontribusinya terhadap topik masalah yang sedang dicarikan solusinya.

Peserta diajak menyusun dan mengkomposisikan Research Findings and Discussion. Dalam bagain temuan penelitian (research findings), peserta diminta untuk menyajikan data yang ditemukan dan harus dihubungkan dengan apakah sudah atau belum menjawab pertanyaan penelitian. Setiap data yang ditemukan, peserta diminta untuk melakukan interpretasi secara mendalam pada setiap item data yang disajikan. Agar data yang ditemukan dikategorikan empirical evidence, maka data atau interpretasi harus didukung oleh theoretical evidence dari reputable journals atau articles. Kedalaman pembahasan ini menjadi lebih 
berbobot ketika para peserta mampu menampilkan penelitian-penelitian sebelumnya dari berbagai artikel jurnal sebagai landasan untuk melakukan interpretasi temuan penelitiannya. Akhirnya, tahapan ini ditutup dengan ulasan mekanisme Menyusun daftar Pustaka ( $A P A$ style).

\section{HASIL DAN PEMBAHASAN}

Kegiatan ini dilaksanakan dalam bentuk Workshop Virtual penulisan artikel dan strategi publikasi di jurnal internasional dan nasional bereputasi. Kegiatan workshop ini berorientasi pada publikasi artikel di jurnal-jurnal kategori bereputasi. Tujuan akhirnya adalah internasionalisasi perguruan tinggi sebagai afiliasi dari para penulis atau peserta workshop, baik dari dosen maupun mahasiswa pasca.

Workshop virtual ini menyajikan materi-materi penulisan artikel dan strategi publikasi di jurnal bereputasi atau akreditasi nasional. Materi penulisan artikel disusun berdasarkan sistematika penulisan artikel umumnya dengan menggunakan sistematika IMRAD (Introduction, Method, Results, Discussion, Implication, \& Conclusion). Pemaparan tiap tahapan ini dapat ditampilkan di Tabel 1 sebagai berikut.

Tabel 1. Materi Penulisan Artikel Model IMRAD

\begin{tabular}{|c|c|}
\hline Parts of Articles & Description \\
\hline Abstract & $\begin{array}{l}\text { An abstract summarizes the mayor aspect of the entire } \\
\text { article/paper in a prescribe sequence that includes: } \\
\checkmark \quad \text { The overall purpose of the study and the research problem } \\
\checkmark \quad \text { The basic design of the study (research method) } \\
\checkmark \quad \text { Mayor findings as the result of the analysis } \\
\checkmark \quad \text { A brief summary of the interpretation and conclusion }\end{array}$ \\
\hline Introduction & $\begin{array}{l}\text { In the writing introduction part, writers should provide information } \\
\text { and set the context in the beginning paragraph. After this, writers } \\
\text { go to introduce specific topics of the research and explain why it } \\
\text { is essential thing to study. Also, writers should mention past } \\
\text { studies to solve the research problems or to answer the research } \\
\text { question. At the end of the paragraph, writers conclude the } \\
\text { introduction by mentioning the research objectives. }\end{array}$ \\
\hline Research Method & $\begin{array}{l}\text { The common parts of the research method cover research } \\
\text { design, data source, data collection, and data analysis. The } \\
\text { steps of this can be elaborated as follows. } \\
\checkmark \quad \text { Introduce the overall methodological approach for } \\
\text { investigating your research problem } \\
\checkmark \quad \text { Indicate how the approach fits the overall research design } \\
\checkmark \quad \text { Describe the specific methods of the data collection you are } \\
\checkmark \quad \text { going to use } \\
\checkmark \quad \text { Explain how you intend to analyze your results } \\
\checkmark \quad \text { Provide background and a rationale for methodologies that } \\
\checkmark \quad \text { Provide a justification for subject selection and sampling } \\
\checkmark \quad \text { procedure } \\
\text { Describe potential limitation }\end{array}$ \\
\hline Results & $\begin{array}{l}\text { In this part, the writer organizes the data as the answer of the } \\
\text { research questions. some parts should be elaborated in this part. } \\
\checkmark \quad \text { The finding section of a study do not prove anything } \rightarrow \text { just } \\
\text { confirm the research problems } \\
\checkmark \quad \text { The page length of this section is set by the amount of types } \\
\text { of data to be reported } \\
\checkmark \quad \begin{array}{l}\text { Avoid providing data that are not critical to answering the } \\
\text { research question }\end{array}\end{array}$ \\
\hline
\end{tabular}




\begin{tabular}{ll}
\hline Parts of Articles & Description \\
\hline$\checkmark$ & $\begin{array}{l}\text { This section also doesn't provide any discussion and } \\
\text { elaboration } \rightarrow \text { be as concise as possible in reporting } \\
\text { research findings }\end{array}$ \\
This part is essential for readers to understand how the research \\
problems are elaborated. There are some issues to consider in \\
composing this part. \\
$\checkmark \quad \begin{array}{l}\text { Think of your discussion as an inverted pyramid } \rightarrow \text { the } \\
\text { discussion from the general to the specific, linking the } \\
\text { findings to literature, theory, then to practice }\end{array}$ \\
$\checkmark \quad \begin{array}{l}\text { Use the same key terms, narrative style, and verb tense } \\
\text { (present) that you used when describing the research }\end{array}$ \\
$\checkmark \quad \begin{array}{l}\text { problem in the intro } \\
\text { Begin by briefly re-stating the research problem you are } \\
\text { investigating and answer the research questions }\end{array}$ \\
$\checkmark \quad \begin{array}{l}\text { Before concluding the discussion, identify potential } \\
\text { limitations and weaknesses }\end{array}$ \\
$\checkmark \quad \begin{array}{l}\text { The discussion section should end with a concise summary } \\
\text { of the principal implication of the findings } \\
\text { Implication }\end{array}$ \\
$\checkmark \quad \begin{array}{l}\text { Write a paragraph or two of discussion for each implication. } \\
\text { In each paragraph, state the Implication for Practice and link } \\
\text { to the finding in your study. }\end{array}$ \\
$\checkmark \quad \begin{array}{l}\text { Then provide a discussion that shows how practice could } \\
\text { be applied or how a specific audience will benefit. } \\
\text { State your conclusions in clear, simple language } \rightarrow \text { Re- } \\
\text { state the purpose of your study then states how your } \\
\text { findings differ or support those of other studies and why } \\
\text { Provide a synthesis of arguments presented in the paper to } \\
\text { show how these converge to address the research problem } \\
\text { and the overall objectives of your study } \\
\text { Indicate opportunities for future research if you haven't } \\
\text { already done so in the discussion section of your paper. } \\
\rightarrow \text { Highlighting the need for further research that provides } \\
\text { the reader with evidence that you have an in-depth }\end{array}$ \\
$\checkmark \quad \begin{array}{l}\text { awareness of the research problem } \\
\text { Pay attention to the targeted journal reference style. }\end{array}$ \\
Conclusion
\end{tabular}

Menulis karya ilmiah berupa artikel hasil penelitian membutuhkan proses mendalam dalam menurunkan ide atau gagasan yang sudah dibahas dalam dokumen penelitian. Hal ini senada dengan Saver (2007) dan Trevorrow dan Martin (2020) yang menyatakan menulis artikel harus mempelajari keterampilan-keterampilan seperti memilih topik yang tepat, keahlian mengatur tabel dan figure grafik untuk menampilkan data penelitian, menguasai topik yang ditulis, dan memiliki kepandaian dalam merangkai Bahasa ilmiah dalam artikelnya. Harapannya, keahlian-keahlian tersebut harus dimiliki oleh peserta workshop virtual penulisan karya ilmiah ini.

Dalam menulis abstrak artikel, peserta atau penulis diminta untuk memperhatikan tujuan penelitian dan masalah penelitian. Peserta juga disarankan untuk memberikan burning issue dalam satu kalimat agar menarik minat pembaca sebelum menuliskan tujuan penelitian (Watson, 2013; Watson 2021). Di bagian abstrak juga, peserta diminta untuk menjelaskan desain penelitian yang digunakan secara singkat. Bagian-bagian yang harus muncul di desain penilitian meliputi metode, objek atau subjek penelitian, instrument pengumpulan data, dan analisis data. Selanjutnya, abstrak juga harus memberikan gambaran singkat terkait temuan penelitian. Temuan penelitian ini penting karena menginformasikan kepada pembaca jawaban atas permasalahan penelitian (Haerazi et al., 2019; Tarverrow \& Martin, 2020). Akhirnya, di bagian akhir abstrak, peserta diminta untuk memberikan kesimpulan berdasarkan jawaban atas penelitiannya. 


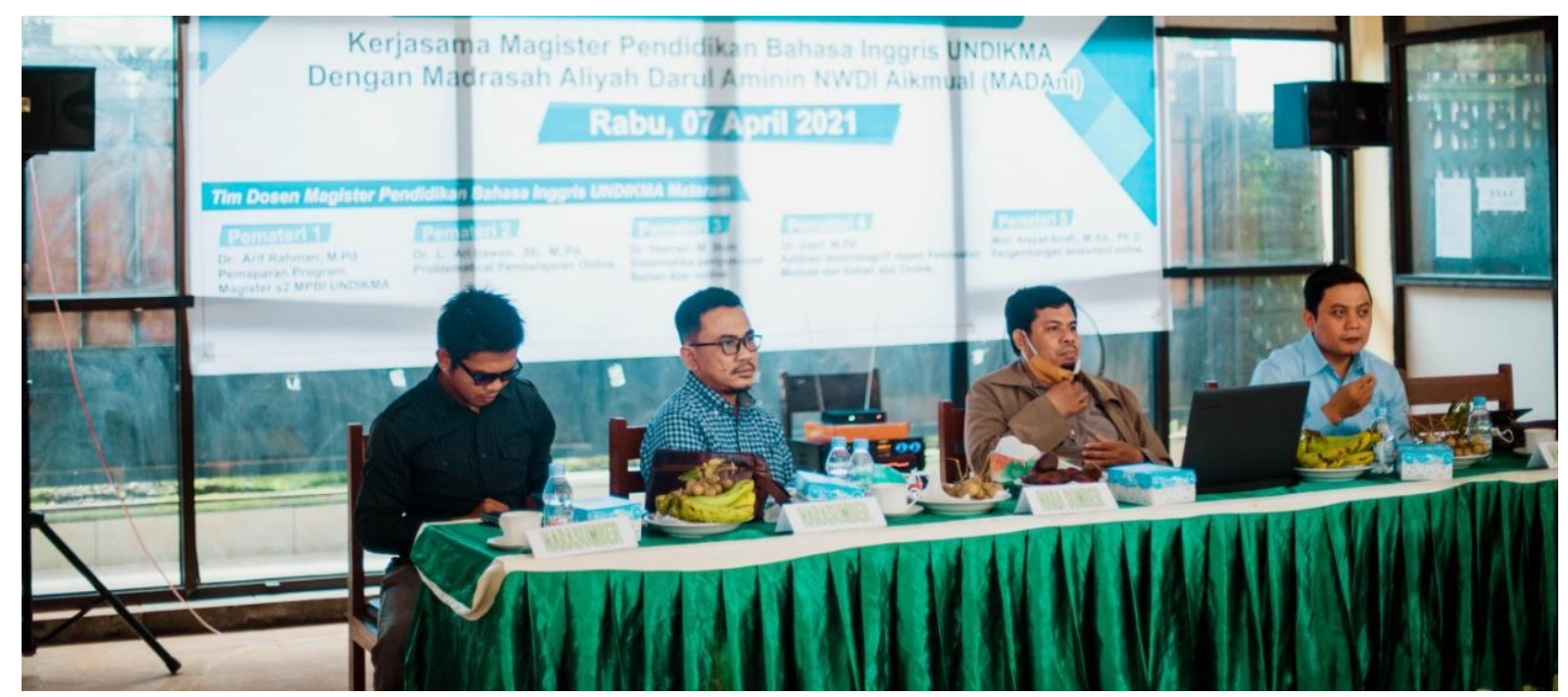

Gambar 1. Narasumber Workshop Virtual

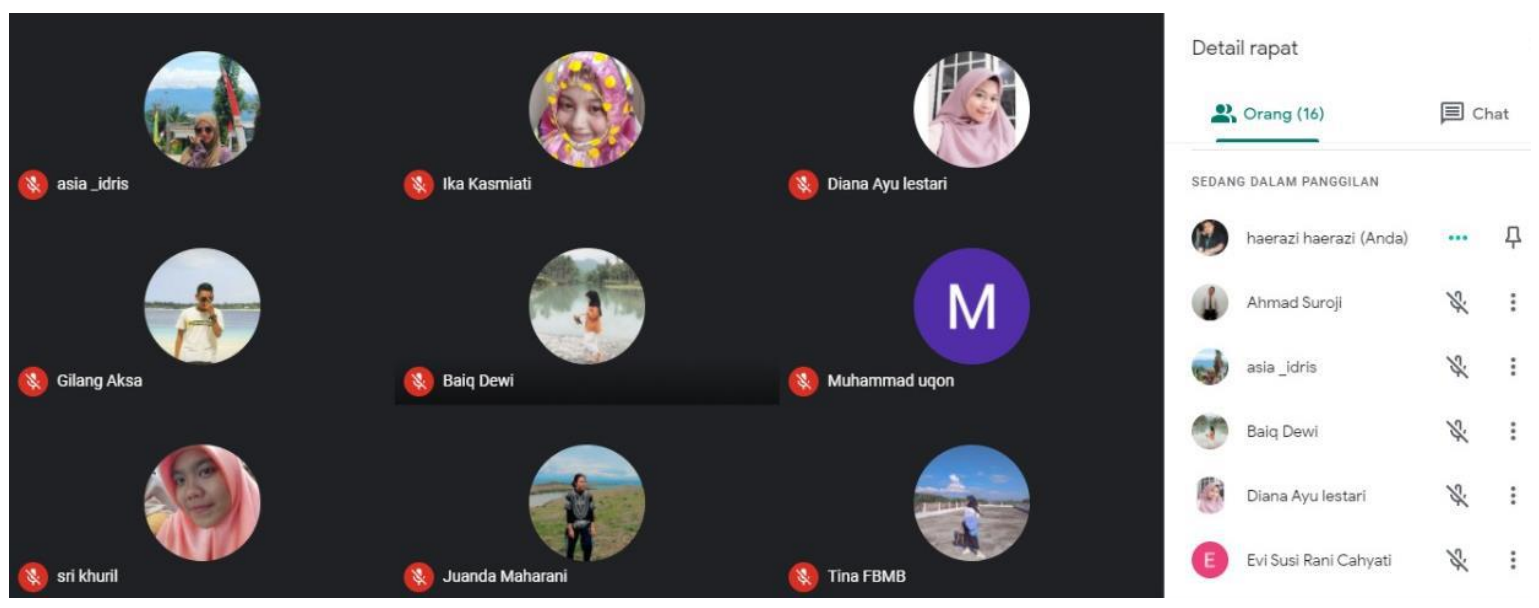

Gambar 2. Peserta Wokshop Virtual Kelompok 1

Pada tahapan penulisan pendahuluan (introduction), peserta mengalami kesulitan untuk menulis burning issue untuk menarasikan masalah penelitian yang hadapi. Pada situasi ini, peserta diajak untuk membaca 5-10 artikel internasional bereputasi yang memiliki kesamaan topik. Peserta diminta untuk melakukan draft kalimat isu-isu hangat ditulis dalam setiap artikel yang dibaca. Dalam beberapa menit, diskusi berjalan dengan baik. Peserta mampu memulai menulis paragraph ke paragraph untuk menyusun pendahuluan artikel yang baik. Penulisan bagian introduction harus diikuti dengan narasi yang baik dalam menyampaikan informasi isuisu penelitian yang sedang dan sudah dilakukan sesuai up-date pengetahuan (Watson, 2021). Di samping itu, peserta harus mampu mengelaborasi topik penelitiannya dan menjelaskan kenapa topik itu penting diketahui secara internasional (Reschke-Hernandez, 2014). Untuk mendukung pernyataan ini, peserta diminta untuk mendukung klaim ini dengan merujuk kepada artikel-artikel internasional.

Pada tahapan pemilihan literature review, peserta diminta untuk memahami setiap isu yang dimunculkan dalam penelitiannya. Memahami secara komprehensif terkait isu-isu yang sedang dielaborasi dalam artikel memudahkan peserta untuk menyusun teori atau konsep untuk menopang isu penelitian yang sedang ditulis. Hal ini senada dengan Haerazi et al. (2019) yang menyatakan penulisan kajian Pustaka atau literature review harus merujuk pada isu-isu yang diangkat dalam penelitian. Hal ini bertujuan untuk menopang penelitian dari beberapa ahli dimana secara ilmiah topik penelitian mendapat sokongan teori yang cukup. 
Dengan pemaparan yang mendalam, peserta mampu memahami dengan baik bagaimana seharusnya kajian pustaka ditulis dalam artikel.

Setelah memahami penulisan kajian pustaka, peserta diajak untuk memfokuskan diri pada metode penelitian. Bagian ini cukup membutuhkan keahlian sendiri bagi peserta untuk memahami cara kerja penelitian mereka. Dalam artikel, menyusun metode penelitian berbeda dengan di skripsi atau tesis (Haerazi et al., 2019; Watson, 2021). Dalam artikel, penulis diharuskan menjelaskan secara singkat, jelas, dan padat terkait cara kerja penelitian dilaksanakan. Dalam workshop virtual ini, peserta dibagi beberapa kelompok sesuai dengan metode penelitian yang diminati.

\section{Academic Writing}

Presented by Dr. Haerazi, M.Hum.

Managing Editor, JOLLT (Journal of Languages and Language Teaching)

Discussion Topic:

Drafting an article and How to submit

it to Journals (reputable journals)

\section{Jadikan Penulisan Karya Ilmiah}

$\underline{\text { Senang dan }} \underline{\text { Seru }}$

Lokakarya Singkat Penulisan SS

SITI MINA TAMAH

UNIKA WIDYA MANDALA SURABAYA

Gambar 3. Materi Presentasi Pembicara Wokrshop

Dalam menyusun metode penelitian, peserta diminta untuk memperhatikan bagianbagian penting dalam metode yang ditulis, misalnya desain penelitian, instrumen penelitian, teknik pengumpulan data, dan analisis data. Peserta diajak untuk berpikir dan memahami dengan baik bagaimana di artikel-artikel berepuatasi internasional menulis bagian metode penelitian. Artike ilmiah diharuskan menjelaskan bagaimana cara kerja penelitian dilaksanakan, bukan menjelaskan definisi setiap item metode penelitian. Dalam bagian ini juga, peserta sebisa mungkin meberikan batasan penelitian yang dilaksanakan. Hal ini senada dengan Reschke-Hernandez (2014) yang menyarankan dalam mengkomposisikan bagian metode penelitian, penulis harus memberikan jastifikasi pemilihan metode, desain, subjek penelitian, dan batasan potensial dalam penelitian tersebut.

Setelah penulisan metode penelitian, peserta diajak untuk memahami bagaimana menyajikan dan menyusun temuan penelitian (research findings) dan pembahasan (discussion). Untuk Menyusun temuan penelitian, peserta diminta untuk memperhatikan pertanyaan penelitiannya. Susunan penyajian temuan penelitian didasarkan pada jawaban pertanyaan penelitian. Jawaban pertanyaan penelitian disajikan sesuai dengan data yang ditemukan. Menurut Haerazi (2020), penyajian data di bagain research finding tidak perlu menambahkan pembahasan secara mendalam. Pembahasan mendalam disajikan di bagain discussion dari artikel. Di bagian discussion, peserta diminta untuk mengelaborasi hasil penelitiannya dari isu umum ke isu yang lebih khusus. Lalu, isu tersebut dihubungkan dengan kajian teori yang ada. Dengan narasi yang baik, peserta juga diminta menghubungkannya dalam konteks praktik di lapangan.

\section{KESIMPULAN}

Pengabdian ini dapat membantu peneliti (dosen pemula dan mahasiswa pascasarjana) menulis dan mempublikasikan artikel di jurnal nasional bereputasi dan internasional bereputasi secara efektif dan efisien. Pengabdian ini berbentuk Virtual-Based Active Participatory Action. Model penulisan artikel yang dihasilkan adalah model IMRAD. Berdasarkan hasil pengabdian ini, workshop virtual ini dapat memberikan gambaran yang cukup kepada peserta untuk menulis dan publikasi ilmiah di jurnal bereputasi nasional dan internasional sebagai salah satu cara untuk nasionalisasi dan/atau internasionalisasi perguruan tinggi. 


\section{REKOMENDASI}

Kegiatan-kegiatan lain itu diharapkan untuk mengembangkan pengalaman mereka dalam penulisan karya ilmiah. Misalnya, workshop khusus bagi dosen atau mahasiswa pasca untuk dilatih dalam pengembangan wawasan metodologi penelitian.

\section{UCAPAN TERIMAKASIH}

Tim pengabdian pasca mengucapkan banyak terima kasih yang tiada terhingga kepada pihak-pihak yang terkait yang telah membantu kegiatan ini terlaksana sampai berakhir. Terima kasih juga kami ucapkan kepada para pejabat UNDIKMA yang telah memberikan ijin akademik untuk melaksanakan pengabdian ini. Akhirnya, semoga pengabdian ini bermanfaat untuk para peserta wokshop virtual.

\section{DAFTAR PUSTAKA}

Arsyad, S., \& Adila, D. (2018). Using local style when writing in English: the citing behaviour of Indonesian authors in English research article introductions. Asian Englishes, 20(2), 170-185. https://doi.org/10.1080/13488678.2017.1327835

Boyle, J., Ramsay, S., \& Struan, A. (2019). The Academic Writing Skills Programme : A model for technology-enhanced, blended delivery of an academic writing programme The Academic Writing Skills Programme: A model for technology-. Journal of University Teaching and Learning Practice, 16(4).

Crosthwaite, P. (2018). Grammatical complexity in academic English Douglas Biber Bethany Gray 2016. Cambridge: Cambridge University Press, I + 276. World Englishes, 37(1), 140-141. https://doi.org/10.1111/weng.12309

Haerazi, H., Irwansyah, D., Juanda, J., \& Azis, Y. A. (2018). Incorporating intercultural competences in developing English materials for writing classes. Journal of Language Teaching and Research, 9(3), 540-547. http://dx.doi.org/10.17507/jitr.0903.13

Haerazi, H., \& Irawan, L. A. (2019). Practicing genre-based language teaching model to improve students' achievement of writing skills. IJELTAL (Indonesian Journal of English Language Teaching and Applied Linguistics), 4(1), 9-18. http://dx.doi.org/10.21093/ijeltal.v4i1.246

Haerazi, H., Irawan, L., Rahman, A., Jupri, J., \& Warta, I. (2020). Publikasi Ilmiah untuk Akselerasi Kenaikan Pangkat Guru Bahasa Inggris SMP Negeri Se-Lombok Tengah. Sasambo: Jurnal Abdimas (Journal of Community Service), 2(1), 33-39. doi: https://doi.org/10.36312/sasambo.v2i1.191

Haerazi, H., \& Irawan, L. A. (2020). The effectiveness of ECOLA technique to improve reading comprehension in relation to motivation and self-efficacy. International Journal of Emerging Technologies in Learning (IJET), 15(01), pp. 61-76. doi: http://dx.doi.org/10.3991/ijet.v15i01.11495

Hasegawa, G. R. (2002). Toward better writing. American Journal of Health-System Pharmacy, 59(1), 31-31. https://doi.org/10.1093/ajhp/59.1.31

Listyani, L. (2017). Academic Writing Students' Affective Reactions towards Joint Reconstruction Phase of Reading to Learn. Celt: A Journal of Culture, English Language Teaching \& Literature, 17(2), 251. https://doi.org/10.24167/celt.v17i2.1206

Reschke-Hernandez, A. E. (2014). Writing scientific research articles: Strategy \& steps. Journal of Music Therapy, 51(4), 396-399. https://doi.org/10.1093/imt/thu033

Morgan, D. N. (2010). Writing Feature Articles With Intermediate Students. The Reading Teacher, 64(3), 181-189. https://doi.org/10.1598/RT.64.3.3

Nagata, R., Iguchi, T., Wakidera, K., Masui, F., \& Kawai, A. (2005). Recognizing article errors in the writing of Japanese learners of English. Systems and Computers in Japan, 36(7), 54-63. https://doi.org/10.1002/scj.20153

Saver, C. (2007). Ten tips for successful writing and article submission. AORN Journal, 85(2), 273-276. https://doi.org/10.1016/S0001-2092(07)60037-4

Trevorrow, P., \& Martin, G. E. (2020). How to write a research article for MRC. Magnetic Resonance in Chemistry, 58(5), 352-362. https://doi.org/10.1002/mrc.5012 
Tribby, M. (Ed.). (2013). You, the Author: Article Writing Made Easy. In Reinventing the Entrepreneur (pp. 107-116). John Wiley \& Sons, Inc. https://doi.org/10.1002/9781118584064.ch12

Watson, R. (2013). Writing for Publication: The Journal Article. In K. Holland \& R. Watson (Eds.), Writing for Publication in Nursing and Healthcare (pp. 59-93). John Wiley \& Sons, Ltd. https://doi.org/10.1002/9781118702727.ch5

Watson, R. (2021). Writing for Publication: The Journal Article. In K. Holland \& R. Watson (Eds.), Writing for Publication in Nursing and Healthcare (1st ed., pp. 62-97). Wiley. https://doi.org/10.1002/9781119583592.ch5

White, L. (2005). Writes of Passage: Writing an Empirical Journal Article. Journal of Marriage and Family, 67(4), 791-798. https://doi.org/10.1111/j.1741-3737.2005.00175.x 